\title{
Autogenous tooth transplantation: Evaluation of pulp tissue regeneration
}

\author{
Manuel Marques-Ferreira ${ }^{1}$, Maria-Filomena Rabaça-Botelho ${ }^{2}$, Lina Carvalho ${ }^{3}$, Barbara Oliveiros ${ }^{2}$, Eunice- \\ Virgínia Palmeirão-Carrilho ${ }^{1}$
}

${ }^{1}$ DDS, MDS, PhD. MSC. Department of Dentistry, University School of Medicine, Coimbra, Portugal

${ }^{2}$ DMS, MMS, PhD. Department of Biophysics and Biomathematics, University School of Medicine, Coimbra, Portugal

${ }^{3}$ DMS, MMS, PhD. Department of Pathologic Anatomy, University School of Medicine, Coimbra, Portugal

Correspondence:

Departamento de Medicina Dentária

Hospitais da Universidade de Coimbra,

Av. Bissaya Barreto - Blocos de Celas,

3000 Coimbra, Portugal,

m.mferreira@netcabo.pt

\begin{abstract}
Marques-Ferreira M, Rabaça-Botelho MF, Carvalho L, Oliveiros B, Palmeirão-Carrilho EV. Autogenous tooth transplantation: Evaluation of pulp tissue regeneration. Med Oral Patol Oral Cir Bucal. 2011 Nov 1;16 (7):e984-9.

http://www.medicinaoral.com/medoralfree01/v16i7/medoralv16i7p984.pdf
\end{abstract}

Received: 03/03/2010

Accepted:16/01/2011

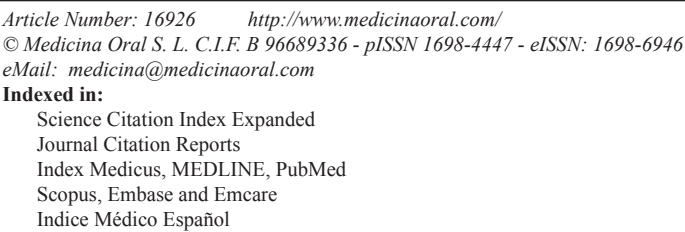

\begin{abstract}
Objective: The aim of this study was to assess the pulp survival that occur in transplants of autologous teeth, by comparing two surgical techniques: the conventional technique (autotransplantation for newly formed alveoli), and an alternative technique, (autotransplants for alveoli in the initial phase of healing). In each surgical techniques were applied, randomly, either saline solution or Emdogain ${ }^{\circledR}$.

Study Design:The study group comprised 26 patents, in which 28 teeth were transplanted to recipient sockets prepared mechanically. Of the 28 teeth transplanted, 4 were intentional replants, and of the remainer, 11 had the apex closed and 13 open. The mean age at the time of transplantation was $22.34 \pm 8.14$ years (mean $\pm \mathrm{SD}$ ). The transplantation were performed by the same operator, with the informed consent of the patient and authorized by the ethical committee of the hospital. Clinical and radiological examinations were performed during 24 to 65 months (48 \pm 12.96 ; $\mathrm{MED} \pm \mathrm{SD}$ ), from 10 days, 1 month, 3 months, 6 months and annually to 5.6 years.

Results: Only two transplanted teeth were lost, due persistent apical periodontitis, and one transplanted patient with open apex missed the treatment. In the teeth with pulp, we needed to perform root canal therapy in 9. In the $73 \%$ of the teeth with closed apex, we needed to perform root canal treatment, with no statistically significant difference found among closed apex and root canal therapy $(\mathrm{p}=0.083)$. In only $8 \%$ of the teeth with open apex did we need to perform root canal treatment, with an association between open apex and root canal therapy $(\mathrm{p}=0.0002)$. The overall success rate was $98 \%$ with significant difference for losses $(\mathrm{p}=0.0001)$.

Conclusions: Although not a frequent procedure, it was concluded that autotransplanted teeth, performed with appropriate surgical care had a good prognosis, and can render a very useful service to the patients.
\end{abstract}

Key words: Autogenous tooth transplantation, pulp tissue regeneration, root canal treatment. 


\section{Introduction}

Autogenous tooth transplantation could be an alternative way to restore the arch if there is a suitable donor tooth available $(1,2)$. Autotransplantation, or autogenous tooth transplantation, is defined as the transfer of a tooth from one position to another in the same individual. This could involve the transfer of impacted, embedded or erupted teeth into extractions sites or into surgically prepared sockets. Successful tooth transplantation depends upon the proper case and patient selection $(2,3)$. It depends upon the vitality of remaining periodontal ligament cells in the donor root, the shape and the site of the recipient socket and the vascularity of the recipient bed (4-6). Immediate replantation of exarticulated teeth is known to have a good prognosis, while transplanted teeth to recipient beds prepared at the same time, show a high prevalence of root resorption (3). To prevent periodontal ligament injuries of the donor tooth during a number of trials for fitting into the bone socket, Kim et al. (7), prepared the bone cavity using a Computer-Aided Rapid Prototyping tooth model, to reduce the extraoral time. To improve nutrition and preserve cell activity in these tissues Nethander et al. (4) and Katayama et al. (5) suggested that teeth should be transplanted to the sockets with regenerative tissues, which may reduce the root resorption following transplantation. The use of the teeth for transplantation is indicated for the following reasons: in adolescents the first permanent molar may frequently be lost due to excessive carious invasion; these same patients have an excellent source of developing third molars; treatment of traumatic accidents where there is loss of teeth and in cases of tooth aplasia. The complications responsible for the failure and loss of the transplanted organ are reabsorptions, of inflammatory cause or substitution. However, several studies show satisfactory results in autotransplants, taking into consideration, as a prerequisite for therapeutic success, a thorough knowledge of surgical procedures and clinical considerations (3). In this context, with this study we aim to assess the pulp changes that occur in transplants of autologous teeth, by comparing two surgical techniques: the conventional technique (autotransplantation for newly formed alveoli), referred to as technique A and an alternative technique, referred to as technique B (autotransplants alveoli in the initial phase of heal- ing). Two different solutions were used in each technique: Emdogain ${ }^{\circledR}$ or saline solution. In each surgical technique either saline solution (SS) or Emdogain ${ }^{\circledR}$ was applied, randomly.

\section{Material and Methods}

This study was performed with patients consulting the Department of Dental Medicine of the Faculty of Medicine, University of Coimbra. These had as criteria for inclusion the fact of being healthy and having good oral hygiene; the acceptance of informed consent for treatment; unrecoverable destruction of the first or second fixed molars, and third molars that presented a formed or forming root; the agenesis of premolar teeth, with indication for orthodontic treatment with extractions and also intentional reimplantation of teeth in which there was failure in non surgical endodontic therapy and impossibility due to the proximity of anatomical structures, of the performance of apical microsurgery. The model for this study was previously approved by the Ethics Committee of the Hospitals of the University of Coimbra and authorized by the Board of the Hospital. The cases were selected with an analysis of panoramic radiographs. In all of the control procedures periapical radiographs were taken using the long-cone parallel technique. Twenty-eight autotransplantations were performed on 26 patients, with an average age of $22.34 \pm 8.14$ years of age (Med $\pm \mathrm{SD}$ ), ranging between 11 and 43 years of age. Of these 26 patients, 12 were male and 14 were female. In two patients, one male and one female, two transplants were performed. Of the performed therapeutics, four teeth were intentional reimplantations (Table 1).

The donor teeth consisted of third molars, maxillary premolars, maxillary canines and a first mandibular molar. The indications for transplants were: 21 teeth lost due to caries; 2 impacted canines, due to the failure of orthodontic traction; 1 canine, due to failure of non-surgical and surgical endodontic treatment, because of pulp calcification; 1 premolar, with failure of surgical endodontic retreatment; 1 lower molar due to failure of nonsurgical endodontic retreatment and the impossibility of surgical endodontic therapy, and 2 premolars, because of agenesis. For topical application to the root surface of the tooth to transplant, Emdogain ${ }^{\circledR}$ was used (Biora AB,

Table 1. Distribution of transplanted teeth, according to sex and radicular maturity.

\begin{tabular}{|c|c|c|c|c|}
\hline Sex & Open apex & Closed apex & $\begin{array}{c}\text { Intentional } \\
\text { reimplante }\end{array}$ & Total \\
\hline Male $(\mathrm{N}=12)$ & 4 & 8 & 1 & 13 \\
\hline Female $(\mathrm{N}=14)$ & 9 & 3 & 3 & 15 \\
\hline Total & 13 & 11 & 4 & 28 \\
\hline
\end{tabular}


Malmo, Sweden) on 14 teeth, or saline (isotonic solution of Sodium Chloride - Paracelsus - Pharmaceutical Industry, SA Porto-Portugal) also on 14 teeth. Emdogain ${ }^{\circledR}$ (EMD) is a derivative of the matrix of enamel, which contains proteins belonging to the amelogenin family, extracted from embryonic porcine enamel. This product not only stimulates the proliferation of pre-odontoblasts and the differentiation of immature osteoblasts, it also has an antibacterial action, due to its $\mathrm{pH}$ being between 4 and 5 and effective in tooth transplantation (8-13). As a negative control, we used saline solution. It was used as a local anesthetic, the lidocaine hydrochloride anhydrous, $20 \mathrm{mg} / \mathrm{mL}$ with adrenaline tartrate, corresponding to $12.5 \mathrm{~g} / \mathrm{ml}$ of adrenaline, Adrenaline xylocaine $^{\circledR}$. The space of the local receptor was evaluated clinically and on the radiographs. The mesi-distal, vestibular-lingual and vertical spaces were evaluated. The donor tooth was measured in the periapical radiography and an acrylic model tooth was made with the same shape and dimensions of the tooth to transplant. This model was used in the preparation of the alveolar receptor (Fig. 1A and B).

Thus, the recipient bed was prepared for immediate transplantation or deferred by ten days. The teeth to be transplanted were cleaned with a polishing brush and toothpaste, and disinfection of the oral cavity was carried out with a solution of chlorhexidine digluconate, $0.1 \%$; clorbutanol hemi-hydrate $0.1 \%$ (Eludril $^{\circledR}$ - Pierre Fabre Dermo-Cosmétique, Portugal). After local anesthetic, atraumatic extraction, avoiding disruption of the root sheath and root buds, was performed. The extra alveolar time was minimal (less than 5 minutes), in order to maintain the vitality of periodontal ligament. Where intentional reimplantation was performed, the extraoral time was longer (about 15 minutes), due to the performance of apicoectomy, for the preparation of the apical cavity and placing the sealing material $\left(\mathrm{MTA}^{\circledR}\right.$ Mineral Trioxide Agregate).

After the topical application of SS or EMD on the root surface of teeth for transplantation, they were gently inserted into the alveolar, slightly below the oclusal plane to avoid premature oclusal contacts (11). The occlusion was checked and controlled with interarticular paper blue/red $60 \mu \mathrm{m}$, Bausch $\mathrm{KG}^{\circledR}$, (Köln, Germany). The setting of the teeth was done during a period of ten days, using for this purpose, silk yarn $3 / 0$, to cross the occlusal face of the tooth (14).

\section{Postoperative Period}

In all patients an antibiotic was performed, starting 24 hours before the intervention (amoxicillin - 1 gram tablets: 1 tablet each 12 hours), and for a subsequent period of six days. Indications were given for analgesic treatment (paracetamol, $500 \mathrm{mg}$ tablets: 1 tablet each 6 hours, if pain) and the application of an ice-pack on the face, protected with fabric or paper.

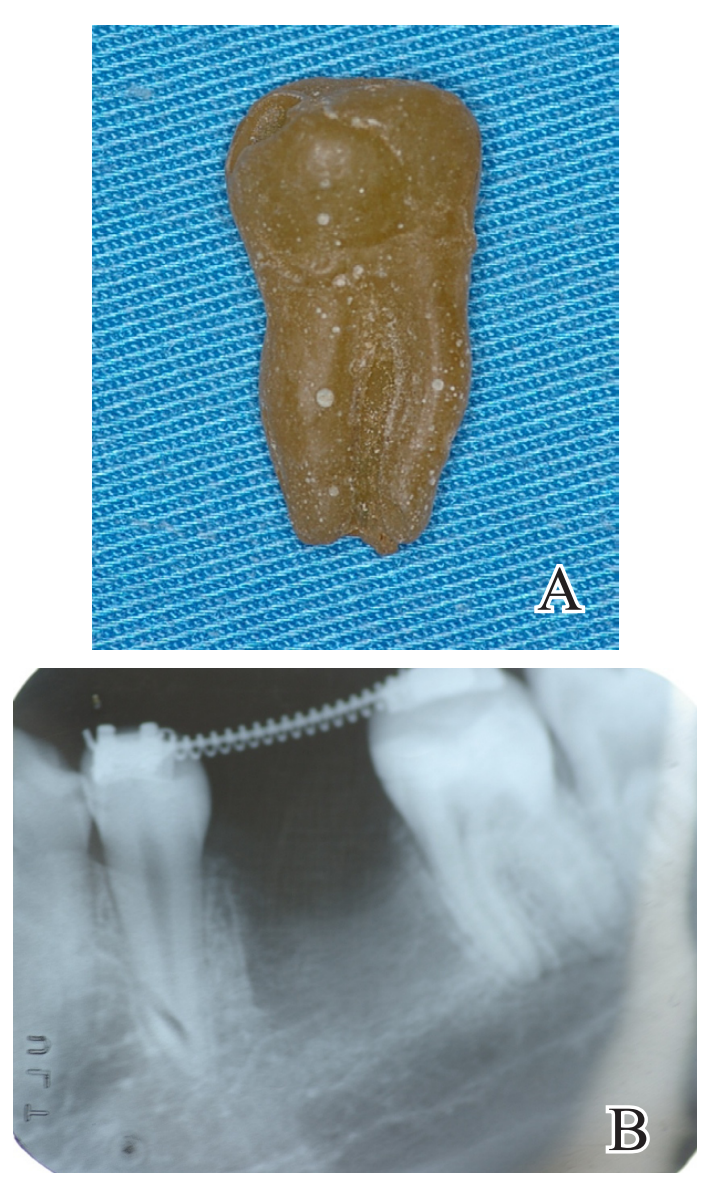

Fig. 1. Image of the model tooth made in acrylic resin (A), and periapical radiograph (B), after the socket was made, in the region of the tooth 46 (clinical case 3 ).

A soft diet was advised for the 48 hours after the transplantation. Chewing with the quadrant was contra-indicated for a period of seven days. Careful oral hygiene was also recommended, followed by a mouthwash with chlorhexidine digluconate to $1 \mathrm{mg} / \mathrm{ml}$ (Eludril ${ }^{\circledR}$ - Pierre Fabre Dermo-Cosmétique, Portugal), diluted in $5 \mathrm{ml}$ of water, to remove the suture, 10 days post-operation. The day after the treatment the patient was observed and questioned regarding the occurrence of pain, swelling and bleeding. Control check-ups were done after 10 days, one month, three months, six months and annually after the transplantation. In each control check-up, a radiographic examination, observation of the gums, the marginal groove, dental mobility and sensitivity testing to cold and percussion were performed. These data were all referenced in the previously defined protocol.

Methods of Analysis

Periapical radiographs by the orthogonal technique were taken, and evaluated according to the existence of periapical pathology, the state of root development, the presence of apical closure and the state of the hard layer of the alveolar. For the performance of the radiographs, 
a generated X-ray source was used, a portable device Port-X II (Genoray Co. Ltd.) producing up to $60 \mathrm{kVp}$, for a current intensity of $2 \mathrm{~mA}$. The timer was set to the minimum value of $0.03 \mathrm{~s}$. These images were viewed on a computer monitor, using for this purpose, the VixWin Pro Software, version 1.5 (KaVo Dental Gendex Dental Systems, Germany) and a qualitative assessment was done. The maintenance of the pulp vitality and the root development occurs when the donor tooth joints the open apex at the time of being transplanted (14). One of the signs to assess the pulp vitality is the consequent partial or total obliteration of the canal and the root development (14). For the evaluation of root growth, we developed a protocol, as described below, which was adopted in the controls of the teeth with open apex. The periapical radiographs were evaluated on a computer program Nemocef 5.0 ${ }^{\circledR}$ (Nemotec Dental Systems, Spain). This program allowed measurements with approximation to a hundredth of a millimeter to be made. This way we obtained values for the length of the root (from the amelo-cemental junction to the most apical point of the root). The root growth was calculated by subtracting the initial length to the final length of the root. A correction factor was introduced (f), to correct any difference between the initial and final radiographs:

$\mathrm{f}=\mathrm{C} 1$ : $\mathrm{C} 2$, where $\mathrm{C} 1$ corresponds to the height of the crown in the initial radiograph and $\mathrm{C} 2$ to the crown in the final radiograph. The height of the crown was defined as the distance between the midpoint of the line of union of the amelo-cemental junction and the midpoint of the line that joins the tips of the cusps (Fig. 2).

Then the increment of root growth was calculated using the following formula:

$\mathrm{FLR}=\mathrm{FMR} \times \mathrm{f}$

$\mathrm{RI}=\mathrm{CFR}-\mathrm{ILR}$

Where FLR = final length of the root; FMR = final measurement of the root; ILR = initial length of the root and $\mathrm{RI}=$ root increase (15). It was considered that root growth occurred when there was an increase of at least $0.5 \mathrm{~mm}$. The cold test was done with a small ball of cotton soaked in ethyl chloride, placed on the cervical third of the dry tooth, which was isolated with cotton rolls. Whenever a reference of pain existed, its duration was measured in seconds. For the cold test four gradations were considered: $\mathrm{T} 0$ for the absence of response to the test, T1 for a positive response, which ceases when the stimulation ends, T2 for the duration of a response between 6 to 9 seconds and T3 for the duration of sensitivity superior or equal to 10 seconds. The percussion test was performed with the lead of the clinical mirror, exerting a gentle swat on the occlusal surface of the tooth in evaluation. To test the impact felt $\mathrm{P} 0$, for no pain, P1 for the presence of pain and P2 for when the percussion sound was metallic.

Statistical analysis of data
In this clinical study, we used the Chi-square, as proportions were compared. The tests were evaluated at a significance level of 0.05 .

\section{Results}

Of the 28 teeth transplanted, monitored for 24 to 65 months $(48 \pm 12.96$; MED $\pm \mathrm{SD})$, one of these, which had the open apex and appeared only for the first control consultation, was excluded and 4 were intentional reimplantations. For the remaining 23 an endodontic therapy was performed on 9 teeth (39\%), 1 with an open apex and 8 with a closed apex. The remaining 14 teeth were not subjected to endodontic therapy (Fig. 3).

From the results of this clinical study, an analytical evaluation was done, where we found that there were significant differences between teeth with an open apex, in comparison to those which had a closed apex. In these, of the 11 transplants performed it was necessary to perform an endodontic therapy in 8 teeth, corresponding to $73 \%$ of the cases. From the statistical analysis, there is a tendency that the need for endodontic therapy occurs significantly more often $(\mathrm{p}=0.083)$, although this significance is not confirmed to the level of 5\%.

On the 12 teeth with an open apex, it was only necessary to perform an endodontic therapy in one case, corresponding to a value of $8 \%$ and a statistically significant difference $(p=0.0002)$.

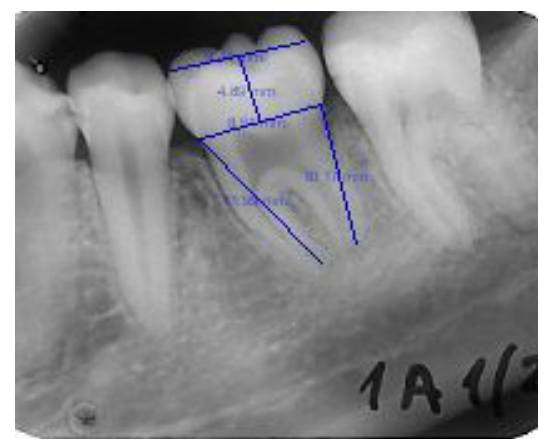

Fig. 2. Method used to analyse root development. $\mathrm{C}=$ crown height; $\mathrm{CR}=$ length of the root.

\section{$n=23$}
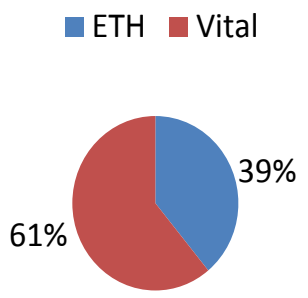

Fig. 3. Endodontic therapy (ETH), performed on the transplanted. 
Table 2. Comparison between the length of the root and revascularization.

\begin{tabular}{|c|c|c|}
\hline & Open apex $(\mathbf{N}=12)$ & Closed apex $(\mathbf{N}=11)$ \\
\hline Length of the root $(\mathrm{mm})$ & $8.07 \pm 2.88$ & $10.82 \pm 1.89$ \\
\hline Revascularization & $\mathrm{n}=11$ & $\mathrm{n}=3$ \\
\hline
\end{tabular}

The relationship between the root length and the revascularization, although this occurred more frequently in teeth with short roots, there no statistically significant difference $(p=0.149)$ (Table 2$)$. The relationship between the two surgical techniques used and the Emdogain ${ }^{\circledR}$ or saline solution, there's no difference.

\section{Discussion}

Studies on the complications of root resorption after tooth transplantation have been based on models in monkeys, rats and dogs $(4,10)$. Transplantation to a recipient bed in which the tissue was under regeneration described by Nethander et al. (4) in 2003, implies that the recipient bed is prepared surgically prior to transplantation and allowed to heal for 5 days. In this study, we used transplant teeth after 10 days of regeneration. The periodontal ligament has demonstrated a remarkable capacity for repair and regeneration.

Katayama et al. (5) demonstrated in dogs that transplanted proliferating tissues promoted reconstruction of a normal periodontium in injured teeth. The effect is probably due to the expression of fibroblast growth factor (FGF) that is a potent mitogen for mesenchymal cells, including bone and periodontal ligament cells (PDL), and also stimulates osteogenic expression of stromal bone marrow cells. They demonstrated that the mRNA expression of FGF and alkaline phosfatase (ALP) increased in proliferating tissue. They concluded that this tissue may promote the regeneration of PDL tissue and prevent ankilosis and root resorption following the transplantation of teeth.

This experimental study demonstrated that there were no differences in the wound healing process between one-stage and two-stage techniques in transplanted teeth. From the results obtained we considered the existence of pulpal necrosis, when the sensitivity tests were negative, when there was pain on the vertical percussion and when radiographically there were signs of inflammatory reabsorption with the presence of a periapical radio transparent area $(15,16)$. These signals allow us to draw conclusions on performing the revascularization or not of the transplanted tooth. On the transplanted teeth that presented an open apex, revascularization occurred in $92 \%$ of cases, which is in agreement with the literature data $(3,16)$. It should also be taken into account that the revascularization and pulpar healing are dependent on the diameter of the foramen and the length of the root (17).
Our results indicate that the shorter the root is $(\mathrm{L}<8.07 \mathrm{~mm})$ and the longer the diameter of the foramen is $(>1 \mathrm{~mm})$, the greater the possibility of pulp revascularization. When during our study clinical signs and radiographic indicators of pulp or periapical pathology appeared, we performed endodontic therapy, which occurred in 39\% of transplants performed. On the other hand, on the teeth with an open apex it was only necessary to perform endodontic therapy on $8 \%$ of them. Although our results are in agreement with the literature an issue that remains controversial is knowing the right time for the performance of endodontic therapy post transplantation. Our option was to do it when there were clinical and radiographic signs compatible with pulp necrosis, and not during a constant time interval right after the transplant, as suggested by other authors (18). In our favor are also results from animal experiments, which refer that there are no differences in performing the endodontic treatment on the 15th or 40th days after the transplantation, since the inflammatory reabsorption was not significantly different (19). According to our results and supported by this experimental study, we can say that the performance of endodontic treatment should be done after the complete healing of the periodontal ligament. This has a great significance and clinical relevance, as a very early endodontic treatment, may find the tooth with some mobility, which is uncomfortable for the patient and for the dentist.

Almost all teeth with no root canal filling showed pulp obliteration. This can be explained by the fact that pulp obliteration increases with time.

These results have clinical implications and suggest that if nonfunctional teeth such as third molars are available, autotransplantation can be considered the treatment of choice. Autotransplantation can be an alternative to dental implant in some patients in whom dental implants become impossible due to inadequate bone support and patients in growing stages.

\section{References References with links to Crossref-DOI}

1. Clokie CM, Yau DM, Chano L. Autogenous tooth transplantation: an alternative

to dental implant placement? J Can Dent Assoc. 2001;67:92-6.

2. Northway WM, Konigsberg S. Autogenic tooth transplantation. The "state of the art". Am J Orthod. 1980;77:146-62.

3. Andreasen JO, Paulsen HU, Yu Z, Schwartz O. A long-term study of 370 autotransplanted premolars. Part III. Periodontal healing subsequent to transplantation. Eur J Orthod. 1990;12:25-37.

4. Nethander G, Skoglund A, Kahnberg KE. Experimental autoge- 
nous tooth transplantation in the dog: a comparison between one- and two-stage surgical techniques. Acta Odontol Scand. 2003;61:223-9.

5. Katayama A, Ota M, Sugito H, Shibukawa Y, Yamada S. Effect of proliferating tissue on transplanted teeth in dogs. Oral Surg Oral Med Oral Pathol Oral Radiol Endod. 2006;101:e110-8.

6. Lindskog S, Pierce AM, Blomlof L, Hammarstrom L. The role of the necrotic periodontal membrane in cementum resorption and ankylosis. Endod Dent Traumatol. 1985;1:96-101.

7. Kim E, Jung JY, Cha IH, Kum KY, Lee SJ. Evaluation of the prognosis and causes of failure in 182 cases of autogenous tooth transplantation. Oral Surg Oral Med Oral Pathol Oral Radiol Endod. 2005;100:112-9.

8. Schwartz Z, Carnes DL Jr, Pulliam R, Lohmann CH, Sylvia VL, Liu Y, et al. Porcine fetal enamel matrix derivative stimulates proliferation but not differentiation of pre-osteoblastic 2T9 cells, inhibits proliferation and stimulates differentiation of osteoblast-like MG63 cells, and increases proliferation and differentiation of normal human osteoblast NHOst cells. J Periodontol. 2000;71:1287-96.

9. Ninomiya M, Kamata N, Fujimoto R, Ishimoto T, Suryono, Kido $\mathrm{J}$, et al. Application of enamel matrix derivative in autotransplantation of an impacted maxillary premolar: a case report. J Periodontol. 2002;73:346-51.

10. Spahr A, Lyngstadaas SP, Boeckh C, Andersson C, Podbielski A, Haller B. Effect of the enamel matrix derivative Emdogain on the growth of periodontal pathogens in vitro. J Clin Periodontol. 2002;29:62-72.

11. Reich PP. Autogenous transplantation of maxillary and mandibular molars. J Oral Maxillofac Surg. 2008;66:2314-7.

12. Jiang J, Goodarzi G, He J, Li H, Safavi KE, Spångberg LS, et al. Emdogain-gel stimulates proliferation of odontoblasts and osteoblasts. Oral Surg Oral Med Oral Pathol Oral Radiol Endod. 2006;102:698-702.

13. Hamamoto Y, Takahashi K, Sakurai H, Akiba K, Izumi N, Kanoh $\mathrm{H}$, et al. The use of enamel matrix derivative (Emdogain) for improvement of probing attachment level of the autotransplanted teeth. Dent Traumatol. 2005;21:336-40.

14. Nasjleti CE, Castelli WA, Caffesse RG. The effects of different splinting times on replantation of teeth in monkeys. Oral Surg Oral Med Oral Pathol. 1982;53:557-66.

15. Bauss O, Schilke R, Fenske C, Engelke W, Kiliaridis S. Autotransplantation of immature third molars: influence of different splinting methods and fixation periods. Dent Traumatol. 2002;18:322-8.

16. Andreasen JO, Borum MK, Jacobsen HL, Andreasen FM. Replantation of 400 avulsed permanent incisors. 2. Factors related to pulpal healing. Endod Dent Traumatol.

1995;11:59-68.

17. Gault PC, Warocquier-Clerout R. Tooth auto-transplantation with double periodontal ligament stimulation to replace periodontally compromised teeth. J Periodontol. 2002;73:575-83.

18. Skoglund A, Tronstad L, Wallenius K. A microangiographic study of vascular changes in replanted and autotransplanted teeth of young dogs. Oral Surg Oral Med Oral Pathol. 1978;45:17-28.

19. Azevedo PC, Moura CC, Zanetta-Barbosa D, Bernadineli N. Time of endodontic treatment in autogenic transplants of mature teeth: histological study in dogs. Oral Surg Oral Med Oral Pathol Oral Radiol Endod. 2007;104:287-93. 